\title{
Efficacy of fluid infusions on the recovery from acute kidney injury in patients administered liposomal amphotericin B: A nationwide observational study
}

\section{Masato Tashiro ( $\nabla$ mtashiro@nagasaki-u.ac.jp )}

Nagasaki University Graduate School of Biomedical Sciences

Yoko Obata

Nagasaki University Hospital

Takahiro Takazono

Nagasaki University Graduate School of Biomedical Sciences

\section{Yuki Ota}

Sasebo City General Hospital

\section{Tomotaro Wakamura}

Sumitomo Dainippon Pharma Co., Ltd

\section{Yui Shiozawa}

Deloitte Tohmatsu Consulting LLC

\section{Ai Tsuyuki}

Deloitte Tohmatsu Consulting LLC

\section{Taiga Miyazaki}

Nagasaki University Graduate School of Biomedical Sciences

\section{Tomoya Nishino}

Nagasaki University Hospital

Koichi Izumikawa

Nagasaki University Graduate School of Biomedical Sciences

\section{Research Article}

Keywords: Liposomal amphotericin B, Acute kidney injury, Fluid infusion, Observational study

Posted Date: April 30th, 2021

DOl: https://doi.org/10.21203/rs.3.rs-405131/v1

License: (c) (i) This work is licensed under a Creative Commons Attribution 4.0 International License. Read Full License 
Page 2/17 


\section{Abstract}

Background: Acute kidney injury (AKI) often develops during the administration of liposomal amphotericin B (L-AMB), a broad-spectrum antifungal drug. However, clinical recovery approaches for AKI patients administered L-AMB have not been well established.

Methods: A retrospective analysis was conducted using data obtained from hospitals throughout Japan. AKI was defined as a $\geq 1.5$-fold increase within 7 days or $\geq 0.3 \mathrm{mg} / \mathrm{dL}$ increase within 2 days in serum creatinine. Renal recovery was defined as a return to creatinine levels below those recorded before the onset of AKI.

Results: Herein, 189 patients had developed AKI following L-AMB administration. Of them, 153 were subsequently assessed to determine the trend in creatinine level after $\mathrm{AKI}$ and 90 patients were assessed for renal recovery. Patients administered $\geq 10 \mathrm{~mL} / \mathrm{kg}$ daily fluid for 7 consecutive days from the onset of AKI had a $63 \%$ recovery rate relative to patients that did not receive infusion ( $35 \%$ recovery rate $(P=$ 0.053)). Although extending the fluid infusion period beyond 7 days did not result in consistent improvement in renal recovery rates, daily fluid volume was found to be positively correlated with renal recovery $(P=0.043)$. On average, patients administered daily fluid infusions of $\geq 10 \mathrm{~mL} / \mathrm{kg}$ had greater reductions in minimum creatinine levels for the first 7 days after AKI compared to patients that did not receive daily fluid infusions. After 7 days of fluid infusion, the mean minimum creatinine levels decreased by $0.21 \mathrm{mg} / \mathrm{dL}$ relative to $0.16 \mathrm{mg} / \mathrm{dL}$ for patients that did not receive daily fluid infusions.

Conclusions: Seven consecutive days of daily fluid infusion from the onset of AKI may promote renal recovery from AKI in patients administered L-AMB, with daily fluid volume positively correlating with the incidence of renal recovery.

\section{Background}

Invasive fungal infections frequently occur in immunocompromised and critically ill patients and are associated with high rates of morbidity and mortality [1-5]. Amphotericin B is a broad-spectrum antifungal drug that covers clinically relevant yeasts and molds that cause mycoses, such as aspergillosis, candidiasis, cryptococcosis, and mucormycosis [6]. However, the use of amphotericin B has been limited because of its high incidence of toxicities, including nephrotoxicity, liver disorder, and hypokalemia [6]. Liposomal amphotericin B (L-AMB), which encapsulates amphotericin B in a liposomal membrane, was developed to reduce the toxicity of amphotericin $B$ while maintaining its antifungal activity [6]. However, this specific liposomal formulation causes reduced tissue distribution in the kidneys and drug-associated nephrotoxicity, including excessive renal vasoconstriction and damage to the renal tubules $[7,8]$. Despite the reduced nephrotoxicity, physicians are reluctant to prescribe L-AMB, especially for patients with renal failure, because of its association with the occurrence of acute kidney injury (AKI) $[9,10]$. 
Several studies have reported that preexisting renal function, the pretreatment and concomitant use of nephrotoxic or antifungal drugs, and L-AMB dosing are associated with AKI in patients administered LAMB [9-11]. Based on these findings, if these factors are carefully considered, the occurrence of renal dysfunction could be prevented in patients administered L-AMB. However, a study conducted in a single facility revealed that high-volume of fluid infusions one week before and one week after the initiation of L-AMB treatment was not associated with recovery from AKI [9]. Although this study suggests that fluid infusion does not contribute to recovery from AKI, it appears that timing, duration, and volume of fluid infusion must still be further scrutinized in a nationwide study. Based on the claims and laboratory data obtained from hospitals throughout Japan, we identified patients who developed AKI following treatment with L-AMB. Thereafter, we investigated the efficacy of fluid infusion before and after the onset of AKI by grouping patients according to treatment with or without fluid infusion, and evaluating their renal recovery outcomes and changes in creatinine levels after AKI.

\section{Methods}

\section{Data source}

This was a retrospective, multicenter, observational study based on electronic medical information data obtained between April 2008 and January 2018. This database, provided by Medical Data Vision Co., Ltd. (MDV), consisted of medical fee reimbursement claims and clinical laboratory results from 345 Japanese hospitals that were operated on the Diagnosis Procedure Combination (DPC) system. The database included the following baseline patient information: age, sex, diagnosis, and comorbidities at admission, coded using the International Classification of Diseases, 10th Revision (ICD-10). In addition, the dates and dosages of all drugs administered for each patient during hospitalization were recorded. All interventional procedures were decoded from the standardized Japanese reimbursement codes. As DPC is an administrative database for inpatients, patient follow-up began on admission day and ended on discharge date, transferal to other hospitals, or death.

\section{Study Design}

In line with the selection criteria described by Takazono et al., [11] we identified patients that developed AKI after receiving the first administration of L-AMB. Thereafter, patients that met the following exclusion criteria were removed (Fig. 1): 1) aged < 18 years old, 2) zero and/or single serum creatinine record available during the specified periods to determine the development of AKI and baseline creatinine levels, 3) nonzero weight and/or height record unavailable, 4) a mean daily dose of L-AMB $>6 \mathrm{mg} / \mathrm{kg}$ per body weight, 5) renal replacement therapy performed on the day of or prior to L-AMB treatment initiation, and 6) AKI developed prior to L-AMB treatment initiation. Furthermore, to determine the trend in serum creatinine levels post-AKI, patients with no recordings of serum creatinine and/or renal replacement therapy during the evaluation period were excluded. For each patient, the evaluation period started on the day after AKI and ended 30 days after AKI, the day of discharge, death, or the day before L-AMB readministration, whichever came first. Finally, to determine the incidence of 30-day renal recovery, we excluded patients with no serum creatinine record between 7 days after AKI and the end of the evaluation 
period as well as unrecovered patients, if they were discharged within 29 days or re-administered L-AMB within 30 days of $\mathrm{AKI}$ onset.

\section{Definitions}

Duration of L-AMB therapy was defined as the time from treatment initiation to discontinuation, with an administration interval $\geq 8$ days. AKI was defined as $a \geq 1.5$-fold increase within 7 days or $\geq 0.3 \mathrm{mg} / \mathrm{dL}$ increase within 2 days in serum creatinine level [12]. Renal recovery was defined as a return to creatinine levels below those recorded before the onset of $\mathrm{AKI}$, the minimum creatinine level within 7 days or 2 days before the onset of AKI, with $\geq 1.5$-fold increase or $\geq 0.3 \mathrm{mg} / \mathrm{dL}$ increase, respectively. For the interventions investigated, daily fluid infusion was determined by whether or not a patient exceeded a specified threshold for total daily volume of extracellular replacement fluid per weight, such as saline and balanced crystalloid solutions, excluding parenteral nutrition with chloride. Discontinuation of L-AMB treatment was defined as the termination of L-AMB administration before or within 3 days after the onset of AKI. Baseline creatinine was defined as the minimum serum creatinine level recorded between 180 days and 7 days before the initiation of L-AMB administration. With the last nonzero weight and height recorded on the day of or within 1 year prior to L-AMB treatment initiation, the conversion to corresponding estimated glomerular filtration rate (eGFR) was derived using a Japanese-specific formula [13]:

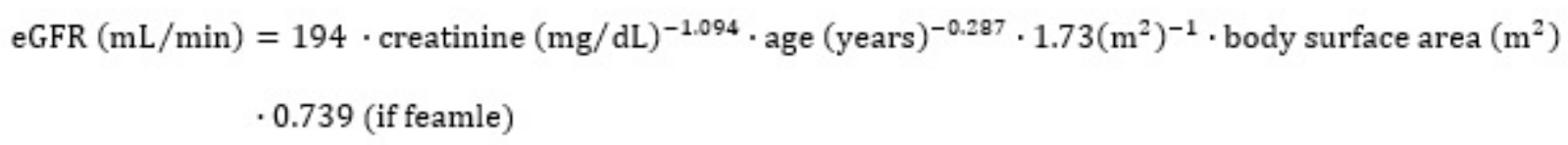

where body surface area $\left(\mathrm{m}^{2}\right)$ was derived with $0.007184 \cdot$ weight $(\mathrm{kg})^{0.425} \cdot$ height $(\mathrm{cm})^{0.725}$. In addition, the change in minimum creatinine level in a given period after AKI was defined as the difference between the creatinine level on the day of AKI and the minimum recorded creatinine level in the period, including the day of AKI.

\section{Statistical analysis}

The Fisher's exact test was conducted to compare the renal recovery incidences between the two categorical groups (patients treated with and without daily fluid infusions). The correlation between renal recovery rates and fluid infusion volume was determined using the Cochran-Armitage trend test. Finally, the Welch's t-test was employed to compare the decline of creatinine levels after AKI between the two groups. A p value $<0.05$ was considered to indicate statistical significance.

\section{Results}

\section{Study population and patient characteristics}


By applying the criteria and definitions described in Materials and Methods, 189 patients were identified to have developed AKI following L-AMB administration. Of these patients, we evaluated 90 that were administered L-AMB and had developed AKI to assess renal recovery (Fig. 1). As shown in Table 1, 56 patients $(62 \%)$ were male and 34 patients $(38 \%)$ were female. Mean age was approximately 65 years-old, mean body mass index (BMI) was $22.0 \pm 4.1 \mathrm{~kg} / \mathrm{m}^{2}$, and mean baseline eGFR was $101.8 \pm 42.8 \mathrm{~mL} / \mathrm{min}$. More than half of the patients $(56 \%, 50 / 90)$ were administered L-AMB in the hematology department. Of the fungal infections identified, aspergillosis was most commonly recognized $(29 \%, 26 / 90)$ among patients. The mean daily dose was $2.7 \pm 0.9 \mathrm{mg} / \mathrm{kg} / \mathrm{day}$ and the duration of L-AMB administration was approximately 20 days. 
Table 1

Characteristics of the patient population

$\begin{array}{lllll}\text { Patient characteristics } & \text { Overall } & \text { Recovery } & \begin{array}{l}\text { Non- } \\ \text { recovery }\end{array} & \begin{array}{l}p- \\ \text { value }\end{array} \\ (n=90) & (n=36, & (n=54, \\ 40 \%) & & & 60 \%)\end{array}$

$\operatorname{Sex}(\%)$

Male

Female

Age (years)

BMI $\left(\mathrm{kg} / \mathrm{m}^{2}\right)$

eGFR at baseline $(\mathrm{mL} / \mathrm{min})$

Duration between the onset of AKI and renal recovery (days)

L-AMB

Mean daily dose (mg/day/ $\mathrm{kg})$

Duration (days)

$56(62 \%) \quad 23(64 \%)$

$34(38 \%) \quad 13(36 \%)$

$64.7 \pm$

16.2

$22.0 \pm$

4.1

$101.8 \pm$ 42.8

NA

A

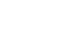

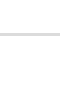

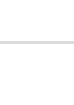

$\begin{array}{llll}2.7 \pm 0.9 & 2.6 \pm 0.7 & 2.8 \pm 1.0 & 0.352 \\ 19.6 \pm & 20.7 \pm & 18.8 \pm & 0.658 \\ 19.2 & 18.4 & 19.7\end{array}$

Treatment department (\%)

The Hematology department

$50(56 \%) \quad 24(67 \%) \quad 26(48 \%) \quad 0.129$

The Internal Medicine department, except for the Hematology

The Surgery department $34(38 \%) \quad 9(25 \%) \quad 25(46 \%) \quad 0.048$ $6(7 \%) \quad 3(8 \%)$ $3(6 \%)$ 0.680

Diagnosis (\%)

Fungal infection

\begin{tabular}{lllll} 
Aspergillosis & $26(29 \%)$ & $10(28 \%)$ & $16(30 \%)$ & 1.000 \\
\hline Candidiasis & $12(13 \%)$ & $6(17 \%)$ & $6(11 \%)$ & 0.532 \\
Cryptococcosis & $6(7 \%)$ & $1(3 \%)$ & $5(9 \%)$ & 0.396 \\
Zygomycosis & $1(1 \%)$ & $0(0 \%)$ & $1(2 \%)$ & 1.000 \\
Aspergillosis, Candidiasis & $0(0 \%)$ & $0(0 \%)$ & $0(0 \%)$ & 1.000
\end{tabular}

BMI, body mass index; eGFR, estimated glomerular filtration rate; L-AMB, liposomal amphotericin B 


\begin{tabular}{|c|c|c|c|c|}
\hline Patient characteristics & $\begin{array}{l}\text { Overall } \\
(n=90)\end{array}$ & $\begin{array}{l}\text { Recovery } \\
(n=36 \\
40 \%)\end{array}$ & $\begin{array}{l}\begin{array}{l}\text { Non- } \\
\text { recovery }\end{array} \\
(n=54 \\
60 \%)\end{array}$ & $\begin{array}{l}\mathrm{p}- \\
\text { value }\end{array}$ \\
\hline Aspergillosis, Cryptococcosis & $1(1 \%)$ & $1(3 \%)$ & $0(0 \%)$ & 0.400 \\
\hline Aspergillosis, Candidiasis, Cryptococcosis & $1(1 \%)$ & $0(0 \%)$ & $1(2 \%)$ & 1.000 \\
\hline Others ${ }^{a}$ & $21(23 \%)$ & $8(22 \%)$ & $13(24 \%)$ & 1.000 \\
\hline Unknown & $18(20 \%)$ & $8(22 \%)$ & $10(19 \%)$ & 0.789 \\
\hline Neutropenia & $4(4 \%)$ & $2(6 \%)$ & $2(4 \%)$ & 1.000 \\
\hline
\end{tabular}

Categorical variables are expressed as frequencies and proportions (\%), while continuous variables are expressed as mean \pm standard deviation. The Welch's t-test was employed to determine the $p$-values for continuous variables while the Fisher's exact test was applied for the categorical variables.

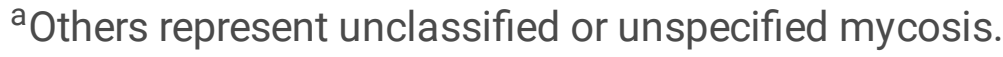

Of the 90 patients, $36(40 \%)$ recovered from AKI. The duration between the onset of AKI and renal recovery was approximately 12 days. Of the 34 patients treated in the Internal Medicine department (excluding the Hematology department), significantly fewer patients (i.e., 9 patients) recovered from AKI (i.e., 25 did not recover from AKI $(P=0.048)$ ). No significant differences were found between the two groups according to sex, age, BMI, eGFR at baseline, mean daily dose and duration of L-AMB, and diagnosis.

\section{Efficacy of fluid infusions on the recovery from AKI in patients administered L-AMB}

To examine the effect of fluid infusions on recovery from AKI, we examined the recovery rates for patients administered fluid infusions. As shown in Table 2, the incidence of renal recovery was similar between patients administered daily fluid infusions of $\geq 10 \mathrm{~mL} / \mathrm{kg}$ for 7 consecutive days before the onset of AKI $(3 / 9,33 \%)$ and those administered $<10 \mathrm{~mL} / \mathrm{kg}$ on at least one day during the period $(27 / 75,36 \%)$. However, patients treated with daily fluid infusions of $\geq 10 \mathrm{~mL} / \mathrm{kg}$ for 2 days before the onset of $A K I$ as well as 2 days and 7 days from the onset of AKI had a higher incidence of renal recovery $(14 / 28,50 \%, 2$ days before $A K I ; 13 / 26,50 \%, 2$ days after $A K I)$ than patients that did not receive infusion $(22 / 62,35 \%, 2$ days before $\mathrm{AKI} ; 23 / 64,36 \%, 2$ days after $\mathrm{AKI}$ ), with the period of 7 days from the onset of AKI yielding the highest incidence $(10 / 16,63 \%$, with fluid; $26 / 74,35 \%$, without fluid; $P=0.053)$. As for other possible effective interventions, we examined L-AMB discontinuation after the onset of AKl; however, higher incidences of renal recovery $(19 / 49,39 \%$, discontinue; $17 / 41,41 \%$, continued, $\mathrm{P}=0.832)$ were not found. 
Table 2

Incidence of renal recovery in patients administered fluid infusions

\section{Renal recovery (\%)}

\begin{tabular}{|c|c|c|c|c|}
\hline Fluid infusion period & $\begin{array}{l}\text { With fluid } \\
\text { infusion }^{a}\end{array}$ & $\begin{array}{l}\text { Without fluid } \\
\text { infusion }^{b}\end{array}$ & $\begin{array}{l}\text { Odds ratio } \\
(95 \% \mathrm{Cl})\end{array}$ & $\begin{array}{l}\mathrm{p}- \\
\text { value }\end{array}$ \\
\hline $\begin{array}{l}\text { For } 7 \text { days before AKI (N } \\
=84)\end{array}$ & $3 / 9(33 \%)$ & $27 / 75(36 \%)$ & $\begin{array}{l}0.890(0.133- \\
4.579)\end{array}$ & 1.000 \\
\hline $\begin{array}{l}\text { For } 2 \text { days before AKI (N } \\
=90)\end{array}$ & $14 / 28(50 \%)$ & $22 / 62(35 \%)$ & $\begin{array}{l}1.806(0.665- \\
4.945)\end{array}$ & 0.247 \\
\hline $\begin{array}{l}\text { For } 2 \text { days after AKI (N = } \\
90)\end{array}$ & $13 / 26(50 \%)$ & $23 / 64(36 \%)$ & $\begin{array}{l}1.771(0.637- \\
4.955)\end{array}$ & 0.242 \\
\hline $\begin{array}{l}\text { For } 7 \text { days after AKI (N = } \\
90)\end{array}$ & $10 / 16(63 \%)$ & $26 / 74(35 \%)$ & $\begin{array}{l}3.036(0.883- \\
11.399)\end{array}$ & 0.053 \\
\hline
\end{tabular}

The Fisher's exact test was performed to determine the odds ratio, $95 \% \mathrm{Cl}$, and p-value. The denominators denote the number of subjects.

$\mathrm{Cl}$, confidence interval; $\mathrm{AKI}$, acute kidney injury

aDaily fluid $\geq 10 \mathrm{~mL} / \mathrm{kg}$ infused consecutively for a given period

${ }^{\mathrm{b}}$ Daily fluid $<10 \mathrm{~mL} / \mathrm{kg}$ infused at least one day during a given period

Additionally, we sought to determine how the volume and duration of fluid infusions affected the incidence of renal recovery in patients. As depicted in Table 3, we evaluated the recovery incidences of patients administered daily fluid infusions between $\geq 5 \mathrm{~mL} / \mathrm{kg}$ and $\geq 30 \mathrm{~mL} / \mathrm{kg}$ consecutively for 2 days and 7 days from the onset of AKI. For the patients that did not receive daily fluid infusions, the recovery rate remained relatively constant at approximately $39 \%$ for all daily fluid volume thresholds. However, for patients administered fluid infusions for 2 days from the onset, a daily volume of $\geq 25 \mathrm{~mL} / \mathrm{kg}$ resulted in the highest renal recovery incidence $(4 / 7,57 \%)$; there was no clear improvement in the recovery rate owing to fluid volume increase. For patients that received fluid infusions for 7 days from the onset, higher incidences of renal recovery were observed when higher daily fluid volumes $(19 / 41,46 \%, \geq 5 \mathrm{~mL} / \mathrm{kg}$; $10 / 16,63 \%, \geq 10 \mathrm{~mL} / \mathrm{kg} ; 5 / 8,63 \%, \geq 15 \mathrm{~mL} / \mathrm{kg} ; 4 / 6,67 \%, \geq 20 \mathrm{~mL} / \mathrm{kg} ; 3 / 3,100 \%, \geq 25 \mathrm{~mL} / \mathrm{kg} ; 1 / 1$, $100 \%, \geq 30 \mathrm{~mL} / \mathrm{kg}$ ) were administered. Although the number of subjects in the higher fluid volume groups was extremely limiting, daily fluid volume was found to be positively correlated with the incidence of renal recovery $(P=0.043$, Cochran-Armitage test $)$. 
Table 3

Incidence of renal recovery in patients infused with the selected daily fluid volume

\section{Renal recovery (\%)}

\section{Daily fluid infusion volume}

For 2 days after $\mathrm{AKI}(\mathrm{N}=90)$

$\geq 5 \mathrm{~mL} / \mathrm{kg}$

$\geq 10 \mathrm{~mL} / \mathrm{kg}^{\mathrm{c}}$

$\geq 15 \mathrm{~mL} / \mathrm{kg}$

$\geq 20 \mathrm{~mL} / \mathrm{kg}$

$\geq 25 \mathrm{~mL} / \mathrm{kg}$

$\geq 30 \mathrm{~mL} / \mathrm{kg}$
With fluid infusion ${ }^{a}$

23/56 (41\%)

$13 / 26(50 \%)$

$8 / 18(44 \%)$

$6 / 13(46 \%)$

$4 / 7(57 \%)$

$2 / 4(50 \%)$

For 7 days after AKI $(\mathrm{N}=90)$

$\geq 5 \mathrm{~mL} / \mathrm{kg}$

$\geq 10 \mathrm{~mL} / \mathrm{kg}^{\mathrm{c}}$

$\geq 15 \mathrm{~mL} / \mathrm{kg}$

$\geq 20 \mathrm{~mL} / \mathrm{kg}$

$\geq 25 \mathrm{~mL} / \mathrm{kg}$

$\geq 30 \mathrm{~mL} / \mathrm{kg}$
19/41 (46\%)

$10 / 16(63 \%)$

$5 / 8(63 \%)$

$4 / 6(67 \%)$

$3 / 3(100 \%)$

$1 / 1(100 \%)$
Without fluid infusion ${ }^{b}$

p-value

0.828

0.242

23/64 (36\%)

0.789

$28 / 72(39 \%)$

0.761

$30 / 77(39 \%)$

0.431

$32 / 83(39 \%)$

1.000

$34 / 86(40 \%)$

0.287

17/49 (35\%)

0.053

26/74 (35\%)

0.258

$31 / 82$ (38\%)

0.213

$32 / 84(38 \%)$

0.061

$33 / 87$ (38\%)

0.400

The Fisher's exact test was performed to determine p-values. The denominators denote the number of subjects.

AKI, acute kidney injury.

aDaily fluid of specified volume or more that is infused consecutively for a given period.

${ }^{b}$ Daily fluid of less than the specified volume that is infused at least one day for a given period.

${ }^{\mathrm{C}}$ Relisted from Table 2.

As depicted in Table 4, we evaluated the incidence of renal recovery for patients administered daily fluid volume of $\geq 10 \mathrm{~mL} / \mathrm{kg}$ and $\geq 25 \mathrm{~mL} / \mathrm{kg}$ for the selected periods from the onset of AKI. Although the recovery incidences were found to be higher with daily fluid infusions than without daily infusions, fluid infusions for 7 consecutive days yielded the highest recovery rates $(10 / 16,63 \%$, volume of $\geq 10 \mathrm{~mL} / \mathrm{kg}$; $3 / 3,100 \%$, volume of $\geq 25 \mathrm{~mL} / \mathrm{kg}$ ) relative to infusions for 2 consecutive days $(13 / 26,50 \%$, volume of $\geq$ 
$10 \mathrm{~mL} / \mathrm{kg} ; 4 / 7,57 \%$, volume of $\geq 25 \mathrm{~mL} / \mathrm{kg})$ or 5 consecutive days $(12 / 24,50 \%$, volume of $\geq 10 \mathrm{~mL} / \mathrm{kg}$; $4 / 5,80 \%$, volume of $\geq 25 \mathrm{~mL} / \mathrm{kg}$ ). However, despite the extremely limited number of subjects employed for these longer periods, extending the fluid infusion period over 7 days was not found to improve the recovery rates in patients administered fluid infusions.

Table 4

Incidence of renal recovery in patients administered infused fluids for the selected periods

\begin{tabular}{|c|c|c|c|}
\hline \multicolumn{4}{|c|}{ Renal recovery (\%) } \\
\hline Fluid infusion period after AKI & With fluid infusion ${ }^{a}$ & Without fluid infusion ${ }^{b}$ & p-value \\
\hline \multicolumn{4}{|l|}{ Daily volume $\geq 10 \mathrm{~mL} / \mathrm{kg}$} \\
\hline For 2 days $(\mathrm{N}=90)$ & $13 / 26(50 \%)$ & $23 / 64(36 \%)$ & 0.242 \\
\hline For 5 days $(\mathrm{N}=90)$ & $12 / 24(50 \%)$ & $24 / 66(36 \%)$ & 0.331 \\
\hline For 7 days $(N=90)^{c}$ & $10 / 16(63 \%)$ & $26 / 74(35 \%)$ & 0.053 \\
\hline For 10 days $(\mathrm{N}=90)$ & $4 / 8(50 \%)$ & $32 / 82(39 \%)$ & 0.709 \\
\hline For 14 days $(\mathrm{N}=80)$ & $3 / 6(50 \%)$ & $30 / 74(41 \%)$ & 0.687 \\
\hline \multicolumn{4}{|l|}{ Daily volume $\geq 25 \mathrm{~mL} / \mathrm{kg}$} \\
\hline For 2 days $(\mathrm{N}=90)$ & $4 / 7(57 \%)$ & $32 / 83(39 \%)$ & 0.431 \\
\hline For 5 days $(\mathrm{N}=90)$ & $4 / 5(80 \%)$ & $32 / 85(38 \%)$ & 0.153 \\
\hline For 7 days $(\mathrm{N}=90)$ & $3 / 3(100 \%)$ & 33/87 (38\%) & 0.061 \\
\hline For 10 days $(\mathrm{N}=90)$ & $1 / 1(100 \%)$ & $35 / 89(39 \%)$ & 0.400 \\
\hline For 14 days $(\mathrm{N}=80)$ & $1 / 1(100 \%)$ & $32 / 79(41 \%)$ & 0.413 \\
\hline \multicolumn{4}{|c|}{$\begin{array}{l}\text { The Fisher's exact test was performed to determine the p-values. The denominators denote the } \\
\text { number of subjects. }\end{array}$} \\
\hline \multicolumn{4}{|l|}{ AKI, acute kidney injury } \\
\hline \multicolumn{4}{|c|}{ 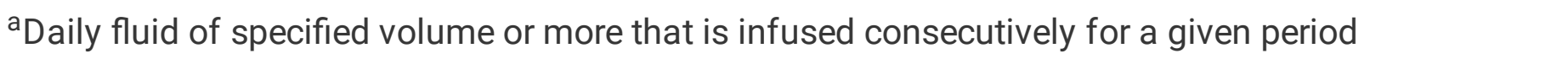 } \\
\hline \multicolumn{4}{|c|}{ bDaily fluid that is less than the specified volume infused at least one day for a given period. } \\
\hline${ }^{\mathrm{C}}$ Relisted from Table 2. & & & \\
\hline
\end{tabular}

Finally, changes in the minimum creatinine levels after the onset of AKI were assessed for 153 patients; these patients had at least one creatinine record and no renal replacement therapy during the evaluation period. As described above, we compared the minimum creatinine levels from the day of AKI onset 
between patients treated with daily fluid infusions of $\geq 10 \mathrm{~mL} / \mathrm{kg}$ and those treated with daily fluid infusions of $<10 \mathrm{~mL} / \mathrm{kg}$ at least one day between the day of AKI and each of the first 7 days following AKI. As shown in Fig. 2, on average, patients administered daily fluid infusions of $\geq 10 \mathrm{~mL} / \mathrm{kg}$ had greater declines in minimum creatinine levels for the first 7 days after the onset of AKI relative to those without daily fluid infusions of $\geq 10 \mathrm{~mL} / \mathrm{kg}$. On day 6 following AKI (i.e., after 7 days of consecutive fluid infusion, including the day of AKI onset), the mean minimum creatinine levels reduced by $0.21 \mathrm{mg} / \mathrm{dL}$ for patients administered daily fluid infusions of $\geq 10 \mathrm{~mL} / \mathrm{kg}$ and $0.16 \mathrm{mg} / \mathrm{dL}$ for patients that were not treated with daily fluid infusions for 7 days, including the day of AKI. During each of the first 7 days, there was no significant difference between the two groups.

\section{Discussion}

In the present study, we retrospectively evaluated patients who developed AKI following treatment with LAMB by employing a dataset obtained from 345 medical facilities in Japan. In addition, we sought to determine the efficacy of interventions on recovery from AKI (Fig. 1). Previously, Yamazaki et al. suggested that intravenous fluid infusion at one week before and after the initiation of L-AMB administration did not contribute to recovery from AKI. Thus, we opted to investigate the potential effect of extracellular replacement fluids on recovery from AKI when an infusion is administered immediately before and after AKI (Table 2). Accordingly, we observed a 1.8-fold increase in the recovery rate for patients administered a daily fluid infusion of $\geq 10 \mathrm{~mL} / \mathrm{kg}$ for 7 days from the onset of AKI $(63 \%$, with fluid; $35 \%$, without fluid; $P=0.053$ ). Although a minimal threshold of $\geq 10 \mathrm{~mL} / \mathrm{kg}$ for daily fluid volume did not result in a significant difference in the recovery incidence, defined as a return to creatinine levels before the onset of $\mathrm{AKI}$, more partial recovery may have been achieved in patients receiving daily infused fluids as they exhibited, on average, greater reductions in minimum creatinine level after AKI (Fig. 2). Furthermore, despite the limited number of subjects, a positive correlation was found between daily minimal fluid volume and recovery rate $(P=0.043$, Cochran-Armitage test), with an approximately 2.6fold increase in recovery rates for those with a daily fluid infusion $\geq 25 \mathrm{~mL} / \mathrm{kg}$ for 7 days relative to those without (Table 3). As extending the fluid infusion period beyond 7 days with a fixed volume did not result in higher recovery rates (Table 4), daily high-volume fluid infusion for 1 week after AKI may be employed to promote recovery from AKI.

To evaluate the efficacy of consecutive fluid infusion over a period of time, a fluid infused group was derived by selecting patients whose fluid infusion volumes exceeded the threshold each day during a specified period and not patients whose mean fluid volume over the corresponding period exceeded the threshold. We employed this definition as the frequency of fluid infusion could be an important factor for renal recovery. For instance, patients with daily fluid infusion of $\geq 10 \mathrm{~mL} / \mathrm{kg}$ for 7 consecutive days from AKI had a recovery rate of $63 \%(10 / 16)$ whereas patients administered a mean fluid infusion volume $\geq 10$ $\mathrm{mL} / \mathrm{kg} / \mathrm{day}$ for 7 days had a recovery rate of $45 \%$ (14/31); the latter was however $27 \%$ (4/15) when patients administered daily fluid infusion were excluded. It should also be noted that fluids were confined to extracellular fluids, such as isotonic saline, that excluded parenteral nutrition with chloride as it was determined as a known risk factor for AKI [14]. 
The implication that daily high-volume fluid infusion immediately after the onset of AKI may be effective for renal recovery is consistent with standard interventions, such as salt loading against amphotericin Bassociated nephrotoxicity [15]. However, such implication differs from the findings of Yamazaki et al. who reported that one week of fluid infusion before and after L-AMB administration initiation does not significantly improve renal recovery rates. This discrepancy between the two studies may be due to differences in the timing of fluid infusion, the frequency of fluid infusion, and the types of infused fluids.

Notably, if no interventions are found to be effective for renal recovery after the onset of AKI, preventative measures will become more critical. Herein, 2 days or 7 days of fluid infusion before the onset of AKI did not significantly increase the incidence of renal recovery; however, the risk factors associated with L-AMBinduced AKI have been previously identified [11]. Special attention to patients possessing these risk factors may thus be required.

Our study had several limitations. First, because the database did not include follow-ups after discharge or hospital transfer, the renal condition of patients was difficult to assess for a sufficiently long period. During the assessment of the incidence of renal recovery, patients were excluded from the sample if they were discharged within 29 days or re-administered L-AMB within 30 days after AKI onset. In addition, despite the inconsistent frequencies of serum creatinine measurements across patients, renal recovery was only evaluated using the available records. Second, the generalizability of the findings presented herein requires further discussion. This is because the database did not contain patients admitted to university hospitals, where infectious disease experts are more likely to work, or facilities with less than 200 beds. Accordingly, our study findings may not be fully representative of patients treated throughout Japan. Third, we could not evaluate AKI by assessing reductions in urine volume, as this parameter could not be obtained from the database employed. Finally, further studies with a large number of subjects from real-world databases and prospective studies are necessary to verify the results obtained herein.

\section{Conclusion}

Based on the findings herein, 7 consecutive days of daily fluid infusion immediately after the onset of AKI may promote recovery from AKI in patients administered L-AMB. For those administered fluid infusions for 7 days from AKI onset, daily fluid volume was found to be positively correlated with the incidence of renal recovery.

\section{List Of Abbreviations}

AKI: Acute kidney injury; BMI: body mass index; Cl: confidence interval; DPC: Diagnosis Procedure Combination; eGFR: estimated glomerular filtration rate; L-AMB: liposomal amphotericin $B$

\section{Declarations}

\section{Ethics approval and consent to participate}


This study was conducted in accordance with the Declaration of Helsinki. The data herein were anonymously processed by the database provider (Medical Data Vision Co., Ltd.) in accordance with the Act on the Protection of Personal Information of Japan and other related regulations. The study received ethical approval from Nagasaki University School of Medicine Research Ethics Committee (approval number 18033038-5). For the usage of unlinkable de-identified data, informed consent was waived by Nagasaki University School of Medicine Research Ethics Committee according to the Japanese Ethical Guidelines for Medical and Health Research Involving Human Subjects by the Ministry of Education, Culture, Sports, Science, and Technology and the Ministry of Health, Labour, and Welfare of Japan.

\section{Consent for publication}

Not applicable.

\section{Availability of data and materials}

The data underlying the results presented in the study are available from Medical Data Vision Co., Ltd., https://www.mdv.co.jp/.

\section{Competing interests}

K. Izumikawa received honorarium and research grant from Sumitomo Dainippon Pharma Co., Ltd; T. Wakamura is a full-time employee of Sumitomo Dainippon Pharma Co., Ltd; and Y. Shiozawa and A. Tsuyuki are full-time employees of Deloitte Tohmatsu Consulting LLC. Deloitte Tohmatsu Consulting LLC receives consulting fees from Sumitomo Dainippon Pharma Co., Ltd.. M. Tashiro, Y. Obata, T. Takazono, Y. Ota, T. Miyazaki, T. Nishino have no conflict of interest.

\section{Funding}

This study was supported by Sumitomo Dainippon Pharma Co., Ltd.

\section{Author's contribution}

M. Tashiro, Y. Obata, T. Takazono, T. Wakamura, T. Miyazaki, T. Nishino, and K. Izumikawa contributed to the study conception and design. Data analysis was performed by Y. Shiozawa. and A. Tsuyuki.

M.Tashiro. drafted the manuscript. M. Tashiro, Y. Obata, T. Takazono, Y. Ota, T. Wakamura, T. Miayazaki, T. Nishino, and K. Izumikiawa reviewed and edited the manuscript. All authors discussed the results and approved the final manuscript.

\section{Acknowledgement}

This work was supported by Sumitomo Dainippon Pharma Co., Ltd. We thank Kenji Baba from Sumitomo Dainippon Pharma Co., Ltd. for supporting the creation of the study plan. Data analysis was conducted by Akinori Takahashi, Masato Homma, and Kumiko Sato from Deloitte Tohmatsu Consulting LLC. 
Sumitomo Dainippon Pharma Co., Ltd. was not involved in the data analysis. Medical writing was supported by Deloitte Tohmatsu Consulting LLC, and proofreading was supported by Editage.

\section{Authors' information}

1Department of Infectious Diseases, Nagasaki University Graduate School of Biomedical Sciences, 1-7-1 Sakamoto, Nagasaki 852-8501, Japan. 2Nagasaki University Infection Control and Education Center, Nagasaki University Hospital, 1-7-1 Sakamoto, Nagasaki 852-8501, Japan. 3Department of Nephrology, Nagasaki University Hospital, 1-7-1 Sakamoto, Nagasaki 852-8501, Japan. 4Department of Respiratory Medicine, Nagasaki University Hospital, 1-7-1 Sakamoto, Nagasaki 852-8501, Japan. 5 Department of Nephrology, Sasebo City General Hospital,

9-3 Hirase-cho, Sasebo, Nagasaki, 857-8511, Japan. 6Medical Affairs Division, Sumitomo Dainippon Pharma Co., Ltd, 1-13-1 Kyobashi, Chuo-ku, Tokyo 104-8356, Japan. 7Deloitte Tohmatsu Consulting LLC, Marunouchi Nijubashi Building, 3-2-3 Marunouchi, Chiyoda-ku, Tokyo 100-8361, Japan

\section{References}

1. Kleinberg M. Aspergillosis in the CLEAR outcomes trial: working toward a real-world clinical perspective. Med Mycol. 2005;43: S289-S2

2. Brown JM. Fungal infections in bone marrow transplant patients. Curr Opin Infect Dis. 2004;17: 3473

3. Marr KA, Carter RA, Crippa F, Wald A, Corey L. Epidemiology and outcome of mould infections in hematopoietic stem cell transplant recipients. Clin Infect Dis. 2002;34: 909-9

4. Morgan J, Wannemuehler KA, Marr KA, Hadley S, Kontoyiannis DP, Walsh TJ, et al. Incidence of invasive aspergillosis following hematopoietic stem cell and solid organ transplantation: interim results of a prospective multicenter surveillance program. Med Mycol. 2005;43: S49-S

5. O'Brien SN, Blijlevens NM, Mahfouz TH, Anaissie EJ. Infections in patients with hematological cancer: recent developments. Hematology Am Soc Hematol Educ Program. 2003;2003: 438-4

6. Stone NR, Bicanic T, Salim R, Hope W. Liposomal Amphotericin B (AmBisome): A review of the pharmacokinetics, pharmacodynamics, clinical experience and future directions. Drugs. 2016;76: 485-500.

7. Barrett JP, Vardulaki KA, Conlon C, Cooke J, Daza-Ramirez P, Evans EG, et al. A systematic review of the antifungal effectiveness and tolerability of amphotericin B formulations. Clin Ther. 2003;25: 1295-1320.

8. Loo AS, Muhsin SA, Walsh TJ. Toxicokinetic and mechanistic basis for the safety and tolerability of liposomal amphotericin B. Expert Opin Drug Saf. 2013;12: 881-895.

9. Yamazaki H, Kondo T, Aoki K, Yamashita K, Takaori-Kondo A. Occurrence and improvement of renal dysfunction and serum potassium abnormality during administration of liposomal amphotericin B in 
patients with hematological disorders: A retrospective analysis. Diagn Microbiol Infect Dis. 2018;90: 123-131.

10. Saito Y, Horita E, Uesaka T, Hayashi Y, Kaizaki Y, Hosoda K, et al. Factor analysis in decreased expression of renal function by liposomal-amphotericin B. J Pharm Health Care Sci. 2014;40: 94-99.

11. Takazono T, Tashiro M, Ota Y, Obata Y, Wakamura T, Miyazaki T, et al. Factor analysis of acute kidney injury in patients administered liposomal amphotericin B in a real-world clinical setting in Japan. Sci Rep. 2020;10: 15033.

12. Kidney Disease: Improving Global Outcomes (KDIGO) Acute Kidney Injury Work Group. KDIGO Clinical Practice Guideline for Acute Kidney Injury. Kidney Inter, Suppl. 2012;2: 1-138.

13. Matsuo S, Imai E, Horio M, Yasuda Y, Tomita K, Nitta K, et al. Revised equations for estimated GFR from serum creatinine in Japan. Am J Kidney Dis. 2009;53: 982-992.

14. Krajewski ML, Raghunathan K, Paluszkiewicz SM, Schermer CR, Shaw AD. Meta-analysis of highversus low-chloride content in perioperative and critical care fluid resuscitation. Br J Surg. 2015;102: 24-36.

15. Mayer J, Doubek M, Doubek J, Horký D, Scheer P, Štĕpánek M. Reduced nephrotoxicity of conventional amphotericin $B$ therapy after minimal nephroprotective measures: animal experiments and clinical study. J Infect Dis. 2002;186: 379-388.

\section{Figures}

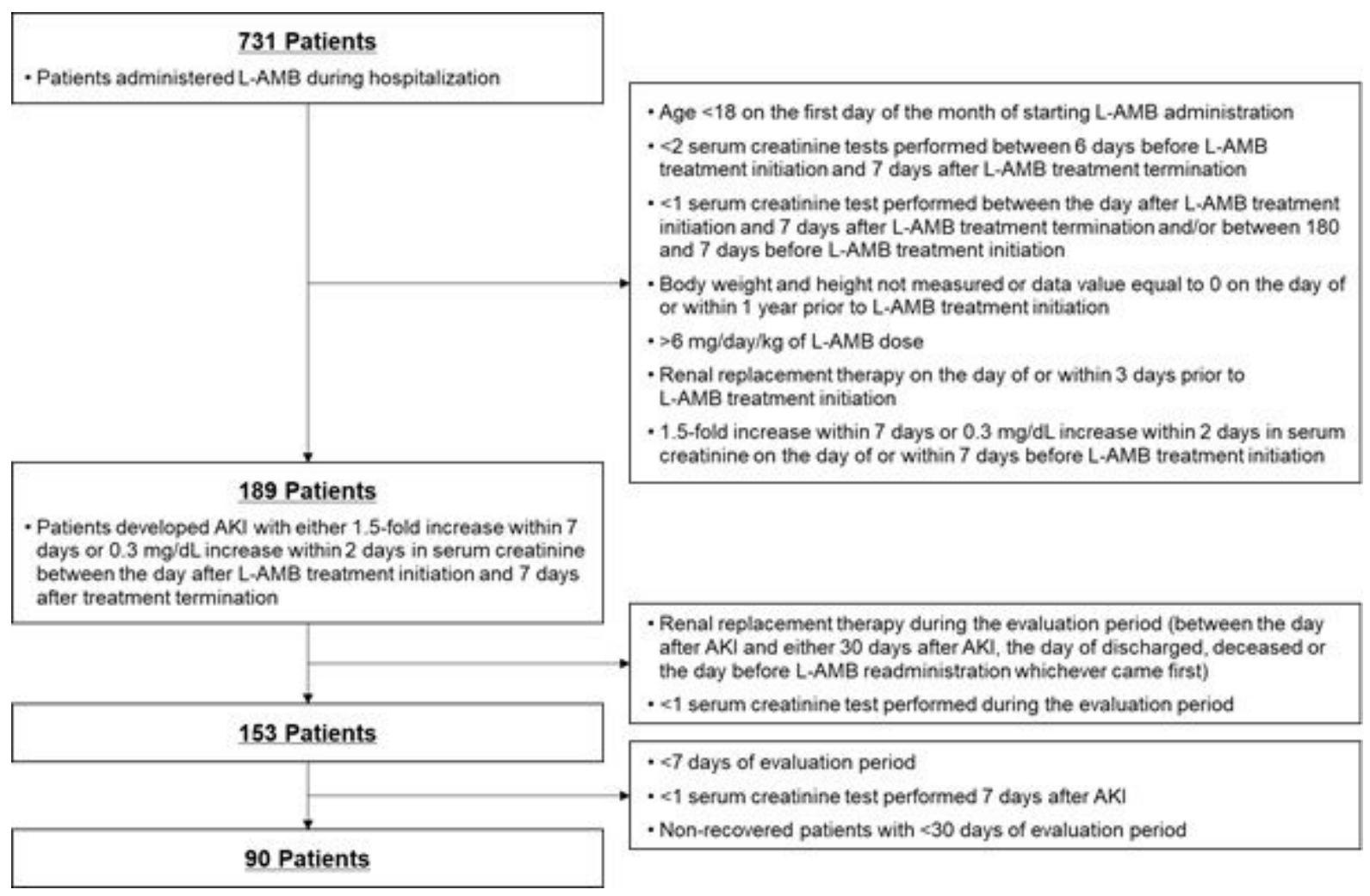

\section{Figure 1}


Flow chart for patient selection

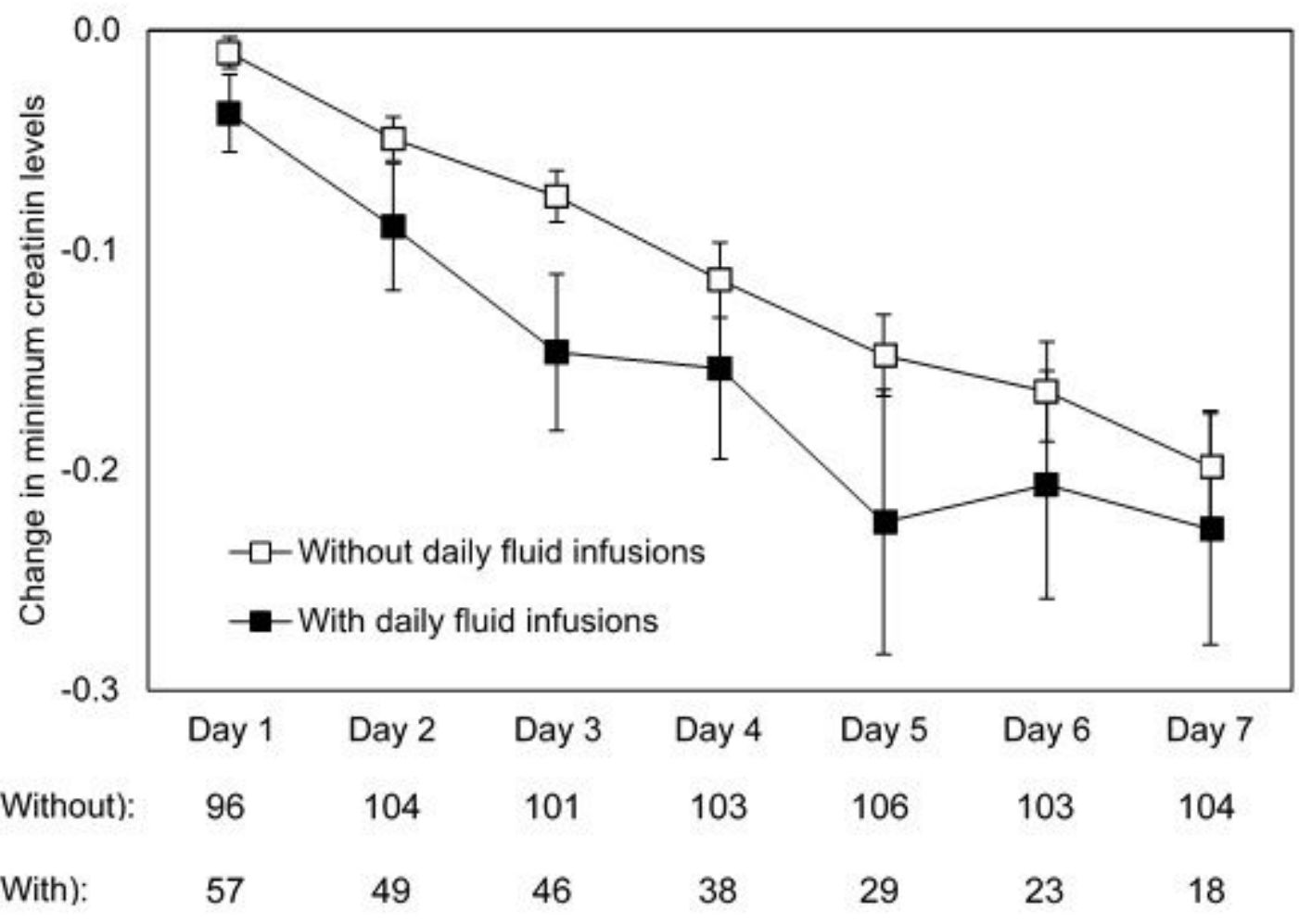

Figure 2

Change in minimum creatinine levels after the onset of AKI. Error bars represent standard error 